\title{
Cardiovascular risk stratification after renal transplant: Is SPECT-MPI the answer?
}

\author{
Karen Kan, MD, ${ }^{\mathrm{a}}$ and Sripal Bangalore, MD, MHA, FACC, FAHA, FSCAI ${ }^{\mathrm{a}}$ \\ a Cardiovascular Clinical Research Center, New York University School of Medicine, New York, \\ NY
}

Received Oct 2, 2016; accepted Oct 3, 2016

doi:10.1007/s12350-016-0705-y

\section{See related article, pp. 295-303}

Chronic kidney disease (CKD) is highly prevalent and affects close to 1 in 10 adults or over 500 million people worldwide. In recent years, its prevalence has been rapidly increasing due to rises in obesity and its metabolic sequelae-diabetes mellitus. ${ }^{1}$ In patients with CKD, cardiovascular disease remains the leading cause of morbidity and mortality, likely due to a combination of traditional cardiovascular risk factors (such as diabetes, hypertension, and hyperlipidemia) and nontraditional risk factors (including inflammation, oxidative stress, and disturbances in mineral bone metabolism). ${ }^{1-5}$ Although CKD is considered a coronary artery disease (CAD) risk equivalent, ${ }^{6,7}$ with a 15-30 times higher cardiovascular mortality compared to the age-adjusted cardiovascular mortality rate in the general population, 8,9 our current means of non-invasive risk stratification in this population remains problematic. Conventional cardiac risk factors are less predictive, ${ }^{10}$ and the presence of typical symptoms (i.e., chest pain) has poor sensitivity $(65 \%)$ and specificity (66\%) for detecting CAD in CKD patients. ${ }^{11}$ As a result, non-invasive stress testing is frequently utilized as a screening modality for the detection of CAD in CKD patients. However, compared to non-CKD cohorts, the accuracy of non-invasive stress testing is also low. ${ }^{12}$

Reprint requests: Sripal Bangalore, MD, MHA, FACC, FAHA, FSCAI, Cardiovascular Clinical Research Center, New York University School of Medicine, New York, NY, 10016, sripalbangalore@ gmail.com

The content is solely the responsibility of the author and does not necessarily represent the official views of the National Heart, Lung, and Blood Institute or the National Institutes of Health.

J Nucl Cardiol 2017;24:304-7.

1071-3581/ $\$ 34.00$

Copyright (c) 2016 American Society of Nuclear Cardiology.
For CKD patients pursuing renal transplant, the evaluation of myocardial ischemia prior to renal transplant is generally considered a routine component of pre-transplant evaluation. ${ }^{13-15}$ Currently, AHA/ACC guidelines state that non-invasive stress testing may be considered in kidney transplant candidates without active cardiac conditions based on the presence of multiple CAD risk factors, regardless of functional status. Although the guidelines acknowledge that the specific number of risk factors used to prompt testing is not entirely clear, it is recommended that the presence of three or more risk factors is reasonable to warrant testing (Class IIb, Level of evidence C). ${ }^{16}$ Whether testing, or more importantly, revascularization for an abnormal test improves outcomes after renal transplant is unknown. ${ }^{17,18}$

It is generally accepted that the risk of CAD is higher among renal transplant patients compared to the general population. Despite aggressive risk stratification and presumably aggressive risk factor control prior to renal transplant, cardiovascular disease remains the most common cause of death following renal transplant with nearly $40 \%$ of patients experiencing a cardiovascularrelated event within 36 months after renal transplant. ${ }^{19,20}$ This has been attributed to higher comorbidity burden but more importantly due to immunosuppressive medications. ${ }^{21}$ However, the guidelines make no recommendations for the evaluation of obstructive CAD in these patients after renal transplant, and there is little consensus about the prognostic role of non-invasive stress testing in these patients. ${ }^{22}$

In this issue of the journal, Abuzeid and colleagues examined the prognostic value of post-transplant myocardial perfusion single-photon emission computed tomography (SPECT-MPI) in a cohort of patients who had undergone renal transplant. From a total of 282 renal transplant recipients, who underwent SPECT-MPI at a single center in Toronto, Canada, at a median of 1.6 years after transplant and were followed for a 
median of 5.7 years, there were 126 (45\%) cardiovascular deaths or cardiovascular disease hospitalization during the follow-up period. The yield from the stress test was fairly high with abnormal summed stress score (SSS) in $41 \%$ of patients, and abnormal summed difference score (SDS) in $31 \%$ of patients. More importantly, a normal SPECT $($ SDS $=0)$ portended a benign prognosis with a cardiac death rate of $0.4 \%$ and an MI rate of $0.6 \%$, rates that approach that of patients without CKD. After adjustment for age, sex, prior myocardial infarction, and cardiovascular risk factors, both an abnormal SSS and an abnormal SDS correlated with progressively increased risk of cardiovascular outcomes in this post-transplant population. Specifically, a higher SDS was a significant predictor of cardiovascular outcomes with SDS 4-6 with adjusted hazards ratio of $2.96(95 \%$ CI 1.72, 5.09, $P<0.001)$ and SDS $\geq 7$ with 3.26 (95\% CI $1.64,6.50, P<0.001)$. Likewise, a SSS 4-6 predicted increased cardiovascular death or hospitalization with adjusted hazards ratio of $2.52(95 \%$ CI $1.51,4.52, P=0.002)$ and SSS $\geq 7$ with $2.61(95 \%$ CI $1.52,4.49, P<0.001){ }^{23}$ The authors concluded that SPECT-MPI predicted cardiovascular outcomes in the post-transplant population, and that this non-invasive modality could be used for risk stratification and prognostication. Other studies on this subject have yielded variable results (Table 1).

One of the strengths of this study is that the authors address a clinically relevant question in an area that currently has little data to guide clinicians. However, as a small, retrospective, observational study, it remains underpowered to fully address the question. Additionally, within the median time from renal transplant to SPECT-MPI of 1.6 years, the authors report that only $19.9 \%$ (56 patients) had the test performed for evaluation of symptoms (i.e., chest pain), while the majority (80.1\%, 226 patients) had SPECT-MPI performed in the absence of symptoms. ${ }^{16}$ It is unclear what criteria clinicians used to determine the patient selection and timing of cardiovascular screening in the asymptomatic group.
Importantly, only a minority (24\%) of patients with an abnormal SPECT-MPI (SSS $>0, n=109$ ) underwent coronary angiography during the follow-up period. Of these, only $62 \%$ (67 patients) were revascularized and the authors do not report the coronary anatomy of the patients who underwent coronary angiography nor whether changes to their medical regimen were made. ${ }^{16}$ It is unclear why only $24 \%$ of those with an abnormal SPECT-MPI underwent coronary angiography. It is likely that the lack of symptoms and potential concerns about the risk of contrast-associated acute kidney injury (AKI) may be some of the driving factors for these low rates, ${ }^{24}$ despite the fact that ultra-low volume contrast protocols for percutaneous coronary intervention are becoming increasingly popular with very low rates of procedure-related AKI. $^{25}$

Even if SPECT-MPI is able to provide prognostic information and identify high-risk patients among the post-renal transplant population, it is still unknown what the optimal treatment strategy should be for these patients. For clinicians, medical therapy often remains challenging given the concern for worsening renal function with administration of agents, such as angiotensin-converting-enzyme inhibitors (ACE-inhibitors) or angiotensin receptor blockers (ARBs), as well as fears about potential drug interactions. Moreover, with the chronic use of immunosuppressive medications (i.e., prednisone and tacrolimus in particular), many of these patients develop new-onset insulin resistance or experience progressively worsening glycemic control of their existing diabetes. ${ }^{26}$ Revascularization strategies also remain problematic as there is often clinical inertia to avoid cardiac catheterization over concern for contrastassociated AKI in patients with a transplanted kidney. Historically, CKD, ESRD, and post-renal transplant patients have been excluded from the major trials of stable ischemic heart disease, leaving our current management practices based on data extrapolated from nonCKD patients. ${ }^{27,28}$ Currently, the on-going, multi-center International Study of Comparative Health Effectiveness

Table 1. Studies of non-invasive stress testing in post-renal transplant patients

\begin{tabular}{lccccc}
\hline & Year & n & $\begin{array}{c}\text { \% Abnormal } \\
\text { stress }\end{array}$ & $\begin{array}{c}\text { \% Underwent coronary } \\
\text { angiography (who had } \\
\text { abnormal stress) }\end{array}$ & $\begin{array}{c}\text { Coronary } \\
\text { angiography } \\
\text { findings }\end{array}$ \\
\hline Abuzeid et al. $^{23}$ & 2016 & 282 & $\begin{array}{l}41 \% \text { abnormal SSS } \\
31 \% \text { abnormal SDS } \\
12 \%\end{array}$ & $24 \%$ & $62 \%$ revascularized \\
Dussol et al. $^{22}$ & 2004 & 97 & $12 \%$ & $100 \%$ & $41 \%$ coronary \\
stenosis $>50 \%$ \\
Derfler et al.
\end{tabular}


with Medical and Invasive Approaches-Chronic Kidney Disease (ISCHEMIA-CKD) trial seeks to determine the optimal approach for stable ischemic cardiovascular disease in patients with advanced CKD (eGFR $<30$ or on hemodialysis). CKD patients with an abnormal stress test will be randomized to either an invasive strategy of cardiac catheterization with revascularization and optimal medical therapy or to a conservative strategy of optimal medical therapy alone. ${ }^{29}$ This trial will offer better insight into the management of this high-risk population that has been historically underrepresented.

In conclusion, Abuzeid and colleagues present interesting and thought-provoking findings, raising the question of whether SPECT-MPI should be used in the post-transplant population for risk stratification and prognostication for cardiovascular disease. As little is known about the role of cardiovascular screening and optimal treatment strategies in this high-risk population, this study will hopefully begin the dialogue for future studies and discussion.

\section{Disclosures}

This article refers to work supported by National Heart, Lung, and Blood Institute grant U01HL117905. Dr Bangalore reports NIH Grant support for the ISCHEMIA-CKD trial.

\section{References}

1. Couser WG, Shah S, Kopple J, Beerkens P, Wilson A, Feehally J, et al. A call to action on world kidney day, 8 March 2007. Kidney Int. 2007;71:369-70.

2. Foley RN, Parfrey PS, Sarnak MJ. Clinical epidemiology of cardiovascular disease in chronic renal disease. Am J Kidney Dis. 1998;32:S112-9.

3. Tonelli M, Wiebe N, Culleton B, House A, Rabbat C, Fok M, et al. Chronic kidney disease and mortality risk: a systematic review. J Am Soc Nephrol. 2006;17:2034-47.

4. Stenvinkel P, Heimburger O, Paultre F, Diczfalusy U, Wang T, Berglund L, et al. Strong association between malnutrition, inflammation, and atherosclerosis in chronic renal failure. Kidney Int. 1999;55(5):1899-911.

5. Ganesh SK, Stack AG, Levin NW, Hulbert-Shearon TE, Port FK. Association of elevated serum phosphate, calcium phosphate product, and parathyroid hormone with cardiac mortality risk in chronic hemodialysis patients. J Am Soc Nephrol. 2001;12:21318.

6. Antman EM, Anbe DT, Armstrong PW, Bates ER, Green LA, Hand M, et al. ACC/AHA guidelines for the management of patients with st-elevation myocardial infarction-Executive summary: a report of the American College of Cardiology/American Heart Association task force on practice guidelines (writing committee to revise the 1999 guidelines for the management of patients with acute myocardial infarction). Circulation. 2004;110:588-636.

7. Hyre AD, Fox CS, Astor BC, Cohen AJ, Muntner P. The impact of reclassifying moderate $\mathrm{CKD}$ as a coronary heart disease risk equivalent on the number of US adults recommended lipid-lowering treatment. Am J Kidney Dis. 2007;49:37-45.

8. Go AS, Chertow GM, Fan D, McCulloch CE, Hsu CY. Chronic kidney disease and the risks of death, cardiovascular events, and hospitalization. N Engl J Med. 2004;351:1296-305.

9. Hachamovitch R, Berman DS, Kiat H, Cohen I, Cabico JA, Friedman J. Exercise myocardial perfusion SPECT in patients without known coronary artery disease: Incremental prognostic value and use in risk stratification. Circulation. 1996;93:905-14.

10. Kasiske BL, Guijarro C, Massy ZA, Wiederkehr MR, Ma JZ. Cardiovascular disease after renal transplant. J Am Soc Nephrol. 1996;7:158-65.

11. Schmidt A, Stefenelli T, Schuster E, Mayer G. Informational contribution of noninvasive screening tests for coronary artery disease in patients on chronic renal replacement therapy. Am J Kidney Dis. 2011;37:56-63.

12. Bangalore S. Stress testing in patients with chronic kidney disease: the need for ancillary markers for effective risk stratification and prognosis. J Nucl Cardiol. 2016;23:570-4.

13. Chew CG, Unger S, Shakib S. Value of myocardial perfusion imaging in renal transplant evaluation. Nephrology. 2013;18:37681.

14. Amin A, Younis G, El-Khatib M, Ali I. Patients with end-stage renal disease: optimal diagnostic and prognostic performance of myocardial gated-SPECT, initial results. Nucl Med Commun. 2013;34:314-21.

15. Thai JN, Abidov A, Jie T, Krupinski EA, Kuo PH. Nuclear myocardial perfusion imaging versus stress echocardiography in the preoperative evaluation of patients for kidney transplant. J Nucl Med Technol. 2015;43:201-5.

16. Lentine KL, Costa SP, Weir MR, Robb JF, Fleisher LA, Kasiske $\mathrm{BL}$, et al. Cardiac disease evaluation and management among kidney and liver transplant candidates: a scientific statement from the American Heart Association and the American College of Cardiology Foundation. J Am Coll Cardiol. 2012;60(5):434-80.

17. McFalls EO, Ward HB, Moritz TE, Goldman S, Krupski WC, Littooy F, et al. Coronary-artery revascularization before elective major vascular surgery. N Engl J Med. 2004;351:2795-804.

18. Dunkelgrun M, Boersma E, Schouten O, Koopman-van Gemert AW, Van Poorten F, Bax JJ, et al. Bisoprolol and fluvastatin for the reduction of perioperative cardiac mortality and myocardial infarction in intermediate-risk patients undergoing noncardiovascular surgery: a randomized controlled trial (DECREASE-IV). Ann Surg. 2009;249:921-6.

19. U.S. Renal Data System: USRDS 2007 Annual data report: Atlas of chronic kidney disease and end-stage renal disease in the United States. 2007.

20. Kasiske BL. Epidemiology of cardiovascular disease after renal transplantation. Transplantation. 2001;72:S5-8.

21. Silkensen JR. Long-term complications in renal transplantation. J Am Soc Nephrol. 2000;11:582-8

22. Dussol B, Bonnet JL, Sampol J, Savin B, De La Forte C, Mundler $\mathrm{O}$, et al. Prognostic value of inducible myocardial ischemia in predicting cardiovascular events after renal transplant. Kidney Int. 2004;66:1633-9.

23. Abuzeid W, Iwanochko RM, Wang X, Kim SJ, Husain M, Lee DS. Prognostic impact of SPECT-MPI after renal transplant. J Nuc Cardiol. 2016;. doi:10.1007/s12350-016-0547-7.

24. Chertow GM, Normand ST, McNeil BJ. "Renalism": inappropriately low rates of coronary angiography in elderly individuals with renal insufficiency. J Am Soc Nephrol. 2004;15:2462-8.

25. Ali ZA, Galougahi KK, Nazif T, Maehara A, Hardy MA, Cohen DJ, et al. Imaging-and physiology-guided percutaneous coronary intervention without contrast administration in advanced renal 
failure: a feasibility, safety, and outcome study. Eur Heart J. 2016; doi:10.1093/eurheartj/ehw078.

26. Shirali AC, Bia MJ. Management of cardiovascular disease in renal transplant recipients. Clin J Am Soc Nephrol. 2008;3:491504.

27. Boden WE, O’Rourke R, Teo K, Hartigan P, Maron D, Kostuk W, et al. Courage trial research group. Optimal medical therapy with or without PCI for stable coronary disease. N Engl J Med. 2007;15:1503-16.
28. BARI 2D Study Group, Frye RL, August P, Brooks MM, Hardison $\mathrm{RM}$, Kelsey SF, et al. A randomized trial of therapies for type 2 diabetes and coronary artery disease. N Engl J Med. 2009; 360:2503-15.

29. ClinicalTrials.gov. Ischemia-chronic kidney disease trial. 2015.

30. Derfler K, Kletter K, Balcke P, Heinz G, Dudczak R. Predictive value of thallium-201-dipyridamole myocardial stress scintigraphy in chronic hemodialysis patients and transplant recipients. Clin Nephrol. 1991;36:192-202. 